\title{
SKI-ING ACCIDENTS IN SCOTLAND
}

\author{
W. Waldie, M.B.,Ch.B.,F.R.C.S., \\ Senior Lecturer in Orthopaedic Surgery, University of Dundee
}

The increasing popularity of ski-ing in scotland in recent years has accounted for an increase in the work of hospitals dealing with accidents resulting from the sport. During the years 1963-66 a survey has been carried out of injuries which required hospital attention at Raigmore Hospital, Inverness, Aberdeen Royal Infirmary, Bridge of Earn Hospital and Dundee Royal Infirmary. The accidents occurred principally at the Cairngorm and Glenshee ski-ing centres and 503 incidents were reported. Minor injuries which did not require hospital care probably accounted for as many again. American authors report an accident rate in ski-ing of between $2-10 / 1000$ skiers per day. In Scotland such a ratio is difficult to assess but it is estimated to lie within these limits.

The largest number of accidents are reported in January and February each year, with a seasonal rise at Easter time in the Cairngorm area.

The youngest injured skier was 7 years and the eldest 67 years. The largest age group involved was between 16-25 years, accounting for $55 \%$ of injuries, and $82 \%$ of injuries occur in skiers under 30 years of age.

In this series injured male skiers outnumber female skiers in the ratio of $3 / 2$.

Injuries in ski-ing result mainly from falling or from direct contact with some hard object. The latter only accounts for $10 \%$ of the injuries reported.

Falls of many varieties occur, the commonest being those occurring at slow speed on relatively level surfaces or in soft snow and those which happened at speed on a steep slope or on firm snow or ice.

The main cause of falling is loss of control, and factors predisposing to this include fatigue, inexperience, poor technique, excessive speed or recklessness, faulty equipment and poor conditions.

The peak hours for accidents are at 12 noon and 4 p.m., with $50 \%$ of incidents between $4-5 \mathrm{p} . \mathrm{m}$. This time probably coincides with the period of maximum fatigue.

The experience of the skier is important, beginners accounting for $58 \%$ of the injured, the expert for only $4 \%$. About $14 \%$ of accidents happen on the very first day on skis. 
Snow conditions at the site of the accident were recorded and soft snow was implicated in $45 \%$ of accidents and icy surfaces in $27 \%$.

The main fault in equipment is the failure of release bindings to function. Injured skiers were wearing 'safety' bindings in $80 \%$ of the incidents, but the release failed to function in $\frac{3}{4}$ of them. Where the release did work the injury was usually to the upper limb, sparing the leg.

An analysis of the injuries sustained showed that the lower limb was involved in $80 \%$ and the upper part of the body in $20 \%$.

Sprains accounted for $45 \%$ of injuries and fractures for $43 \%$, the remaining $12 \%$ covering a variety of injuries such as dislocations, lacerations and contusions.

The most frequent single injury was a sprain of the medial collateral ligament of the knee which was noted in $20 \%$ of cases, followed by fracture of the tibia in $19 \%$ and fracture/sprains of the ankle accounted each for $17 \%$ and $16 \%$ respectively. The most frequently injured joint was the ankle in $33 \%$ of injuries, followed by the knee in $25 \%$.

The conclusion of this investigation would suggest that the most fruitful field for further research and accident prevention would like in attempting to reduce the very high incidence of accidents to beginners, particularly those setting out to ski for the first time.

A more foolproof and reliable release binding particularly applicable to the novice is required, together with more experience in the initial fitting of such a binding. 